\title{
Flexible Complexity Management and Engineering by Innovative Services
}

\author{
Natalia Kryvinska • Thomas J. Hacker • \\ Fatos Xhafa $\cdot$ Michael Alexander
}

Received: 17 December 2013/Accepted: 21 December 2013/Published online: 8 January 2014

(C) Global Institute of Flexible Systems Management 2014

The management and engineering of innovative services for a global client base in a service economy struggles with continuously increasing complexity (Benedettini and Neely 2012a). To address the problem of growing complexity, one of the objectives of Service Science is to couple "the power of science and engineering to support knowledge workers within complex service environments through knowledge centered technological architectures and solutions" (Bitner and Brown 2008; Paton and McLaughlin 2008). To this end, the creation and delivery of services involve understanding and engineering improvements in the complex processes and relationships that are a part of information inter-operations. For instance, value networks, which have evolved from value chains or grids, are based on the engineering and use of complex web-portals that interconnect large numbers of participants, i.e. different kind of vendors and suppliers, who bring value to the end users (Basole and Rouse 2008). Moreover, the inherent

\footnotetext{
N. Kryvinska ( $\square)$

Department of e-Business, School of Business, Economics and Statistics, University of Vienna, Vienna, Austria

e-mail: natalia.kryvinska@univie.ac.at

T. J. Hacker

Computer \& Information Technology, Purdue University, West Lafayette, IN, USA

e-mail: tjhacker@purdue.edu

F. Xhafa

Department of Languages and Informatic Systems, Technical

University of Catalonia, Barcelona, Spain

e-mail: fatos@1si.upc.edu
}

\section{Alexander}

Institute of Management Science, Vienna University of

Technology, Vienna, Austria

e-mail: michael.alexander@tuwien.ac.at complexity arising from the complex web of relationships between vendors and suppliers of services that changes and evolves over time is a significant challenge. Addressing new problems in this constantly changing environment itself is a challenge that can be met by applying innovative servitization strategies. As Benedettini and Neely (2012a) claim “..., it must be considered that complexity in services can originate from many other sources than the service system". They also state that to consider just service systems or underlying infrastructure complexity is "too narrow to capture the meaning of complexity in services".

Furthermore, the statistical data gleaned from research performed by many industrialized countries shows - that the service economy has evolved to become the largest share apart from the manufacturing and agricultural sectors. As Spohrer et al. (2007) describe: "The growth of the service sector has resulted in part from the specialization and outsourcing of service activities performed inside manufacturing firms". The most illustrative service cases to be pointed as examples are as follows: product design, human resources management, customer relationship management, and IT environment maintenance. This in turn has evolved over time to become an extremely complex environment (Spohrer et al. 2007). Besides, the substance and nature of complex environments is such that any "siloed" stand-alone scientific subject or researcher working within these silos cannot tussle against challenges and achieve a continuing sustainable success (Bitner and Brown 2008; Paton and McLaughlin 2008). Thus, understanding and measuring complexity has always been a topic for variety of researchers and scientific disciplines.

It is incredibly difficult to define and measure the complexity of service delivery systems because of its range of meanings for different subjects and sciences (Benedettini and Neely 2012a). Additionally, "In relatively recent times, 
complexity thinking and complexity research have started to be applied also to management science" (Benedettini and Neely 2012a; Robertson 2004). Consequently, to remain competitive and relevant, service enterprises have shifted their strategy focus beyond cost, quality and technology management towards innovative services leadership. As a result, innovative services are gradually emerging into the unique vending offers of the enterprises in response to the increasingly dynamic, competitive and complex environments (Bullinger et al. 2003). At the same time, the enterprises need to keep their service marketplace constantly developing, being always "one step ahead of their competitors" to ensure that they can meet customer requirements.

In practice, however, reaching these ideals is difficult. The continuously increasing service as well as service systems complexity, especially when confronted with serious real-world challenges such as the lack of clear problem definition ["no unequivocal descriptions of the service contents, the relevant processes and the necessary resources" (Bullinger et al. 2003)] and the lack of transparency as a result of quality problems in general (Bullinger et al. 2003). Other authors also stress that: "There is an urgent need to address the big issues of a society built on complex and often fragmented systems" ( $\mathrm{Ng}$ and Andreu 2012). Ng and Andreu continue: "These value-creating complex service systems encompass a wide range of constellations from businesses to local communities". Similarly, Benedettini and Neely note that: "The shift of manufacturers into services has been described as a process that involves the provision of services of increasing complexity ... Complexity appears to be a characteristic of the services offered, rather than a consequence of the different approaches to complexity that may be taken by individual firms" (Benedettini and Neely 2012b).

To showcase emerging work in this area, this Special Issue focuses on the framework for flexible management and engineering of innovative services, specifically on the flexible complexity management that arises from activities focused on the creation, modeling or delivery of innovative services. Accordingly, our purpose is to provide a systematic exemplification of the flexible complexity management by meanings and roles. Further, we highlight in this special issue various research aspects of the flexible complexity management of innovative services. This issue features works that are the most relevant to the Special Issue theme and reflect realistic, practical considerations.

The paper authored by Fauska et al. "Agile Management of Complex Goods \& Services Bundles for B2B E-Commerce by Global Narrow-Specialized Companies" analyzes the "usage and managing of E-Commerce by global narrowspecialized companies is, as this business strategy represents highly demanded approach to competitive scheme in global markets of goods \& services bundles". Furthermore, the paper contributes to the "limited knowledge regarding agile management of E-commerce by global narrow-specialized companies". The work seeks to "help managers of global narrow-specialized companies to make decisions on investments and execution of E-Commerce strategy".

In the paper entitled "Efficient Managing of Complex Programs with Project Management Services", Stoshikj, et al. examine "complex project management processes and propose understanding of project management tools as a service, both when speaking in software terms and management skills frames". They claim that "Project management can be offered as a service in different forms". Thus, the authors divide the approach onto two parts: "Companies specialized in project management may manage a project for the benefits of third party, using the client's technical knowledge and principles of work", and "Companies that want to manage their projects internally need project management training service and software solution with certain functionalities and characteristics". Moreover, their recommended solution "must follow the company policies in regard to resources, time and cost management, collaboration etc.".

Lepmets et al. in the "The Evaluation of the IT Service Quality Measurement Framework in Industry", target a twofold purpose- on the one side to: "evaluate an IT service quality measurement framework", and on the other side to "refine the IT service quality measurement framework for the IT service industry". The authors also describe "the notion of IT service quality from a holistic point of view". Thus, they consider "the IT service quality measures that could help IT service organizations to understand the quality of the IT services they offer and address the areas where provider-driven IT service improvement is needed". Specifically, they "take a closer look at how process performance relates to other IT service quality measures and to the overall IT service quality".

Stieninger and Nedbal in the "Characteristics of Cloud Computing in the Business Context: A Systematic Literature Review" recognize that "Cloud Computing services have become more cost effective and technically flexible than traditional solutions". In turn, "they (Cloud Computing services) are gaining more and more attention among organizations". However, "there is still disagreement about the exact meaning of Cloud Computing". Thus, the authors evaluate "current status concerning the conceptualization of Cloud Computing research by reviewing and classifying existing scientific literature".

In the paper, "The implementation of innovative services in education by using Cloud infrastructure and their economic aspects", Balco and Gregus deliver "information related to economic aspects of implementation the services based on cloud concept where the process of education was adapted for cloud environment to reduce investment and operation costs of organization". They claim that "Today's 
economic environment requires from suppliers cost effective services for commercial as well as no commercial environments". Thus, they discover that: "The debates regarding this topic are presenting different strategies. In the first group are supporters of traditional technology... On the other hand ... professionals who understand very well the market requirements". And, as result "... nonstandard innovative solutions provide a high level of autonomy for users, flexibility in management and create space for creativity in the future".

Finally, Mladenow et al. "Social Crowd Integration in New Product Development-Crowdsourcing Communities Nourish the Open Innovation Paradigm", investigate "new product development (NPD) using social crowd integration concepts". They emphasize that: "The core of the open innovation paradigm is based on the principle of collecting ideas from external sources into the organization, and bringing those adapted, transformed and enriched ideas to the market". Further, the authors explore a challenge in this field: "However, under the constant pressure of being innovative, companies have to try harder to tap their customers' knowledge and abilities". Additionally, they propose a solution for these pressures: "Crowdsourcing communities provide an arena for a vast amount of consumers to actively participate in innovation processes".

Acknowledgments The guest editors would like to thank Prof. Sushil (Editor-in-Chief of Global Journal of Flexible Systems Management) for an opportunity to launch and consolidate this special issue, as well as providing us with the support during the whole process.

\section{References}

Basole, R. C., \& Rouse, W. B. (2008). Complexity of service value networks: Conceptualization and empirical investigation. IBM Systems Journal, 47(1), 53-70.

Benedettini, O., \& Neely, A. (2012a). Complexity in services: An interpretative framework. Proceedings of 23rd Annual Conference of the Production and Operations Management Society (POMS 2012) (pp. 20-23). Chicago, IL.

Benedettini, O., \& Neely, A. (2012b). Factors influencing service complexity: The perspective of servitized manufacturers European Operations Management Association Conference (EurOMA). 1-5 July, Amsterdam.

Bitner, M.J., \& Brown, S.W. (2008). The service imperative, business horizons, 50th Anniversary Issue, Jan/Feb.

Bullinger, H.-J., Fähnrich, K.-P., \& Meiren, T. (2003). Service engineering-Methodical development of new service products. International Journal of Production Economics, 85, 275-287.

Ng, I., \& Andreu, L. (2012). Guest editorial: Special issue on "research perspectives in the management of complex service systems". European Management Journal, 30(5), 405-409.

Paton, R. A., \& McLaughlin, S. (2008). Services innovation: Knowledge transfer and the supply chain. European Management Journal, 26(2), 77-83.

Robertson, D. A. (2004). The complexity of the corporation. Human Systems Management, 23, 71-78.
Spohrer, J., Maglio, P., Bailey, J., Daniel Gruhl, D., et al. (2007). Steps toward a science of service systems. Computer, 40(1), 71-77.

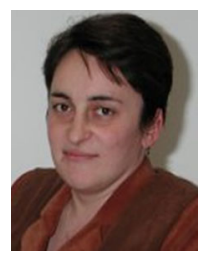

Natalia Kryvinska is the University Lecturer and the Senior Researcher at the eBusiness research group at the University of Vienna's School of Business, Economics and Statistics. She received her Engineering degree in Telecommunications from the National University "Lviv Polytechnics" in Lviv, Ukraine and a $\mathrm{PhD}$ in Electrical\&IT Engineering from the Vienna University of Technology (TU Wien) in Austria. Her research interests include eServices/eBusiness, Service Science, Service Management and Engineering, Service Delivery Platforms, and Complex Service Systems Engineering.

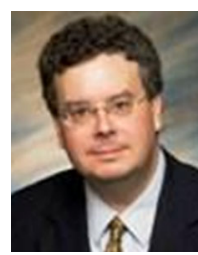

Thomas J. Hacker is an Associate Professor of Computer and Information Technology at Purdue University in West Lafayette, Indiana, USA. He received his B.S. in Physics and B.S. in Computer Science from Oakland University in Rochester, Michigan. He received his M.S. and Ph.D. in Computer Science and Engineering from the University of Michigan, Ann Arbor. His research interests include grid computing, operating systems, networking, high performance computing, and data intensive computing systems.

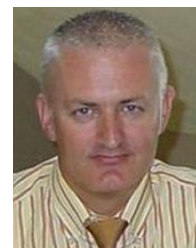

Fatos Xhafa holds a $\mathrm{PhD}$ in Computer Science from the Technical University of Catalonia (UPC), Spain. He was a Visiting Professor at University of London (UK) during 2009-2010 and Research Associate at Drexel University, Philadelphia (USA) during academic term 2004/2005. He is Professor Titular at UPC (Spain). Prof. Xhafa has widely published in peer reviewed international journals, conferences, book chapters and edited books and proceedings in the field. Prof. Xhafa has an extensive editorial and reviewing service and is actively participating in international conferences organization. His research interests include parallel and distributed computing, optimization and networking.

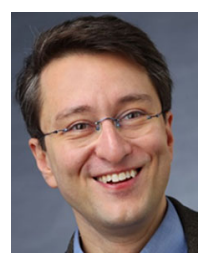

Michael Alexander holds degrees in electrical engineering (TGM), business administration (University of Southern California) and economics (University of Vienna). He is an assistant professor at the Financial Enterprise Management Group at the Institute of Management Science, Technische Universität Wien (TU Wien). His professional experience includes education and product management at IBM, and Alcatel. Prior to TU, he was Product Line Manager for Alcatel ADSL and Optical Access Networks. His research interests include dataflow programming languages, virtualization of system and network management, computer and network security, scenario tree path optimization, ERP system architecture, and Information centric networks. 